\title{
HEROES MAKE YOU THINK
}

\author{
BOGDAN TROCHA
}

\begin{abstract}
Author discusses the mechanisms of mythologization of modern figures of heroes in the latest culture. He also analyzes the competences of the creator of such figures and their relationship with the very process of mythologization. He also describes the causes of this phenomenon in contemporary culture.

Keywords:myth, mythopoeia, mass literature
\end{abstract}

\section{Myth - birth, essence, function}

The myth and mythical message contained in it is important and important for culture and contemporary man, and it is not necessary to convince anyone especially today. Every participant of contemporary culture, be it high, mass or just political culture, can freely list a few mythical figures and quote some mythologies. The problem arises when we begin to look more closely at the myth in search not only of the plot itself, but above all of the discovery of the full content that it brings with it. From the very beginning, when we face the seemingly simple question of what myth is about, we come across significant problems. There is no single definition of myth. There are hundreds of them. So what is myth? Is there only one, some canonical version of myth, or maybe there are many of them? So how to recognize whether I am dealing with a mythical text or only with some form of mythology. These questions give rise to problems not only related to the authorising of what is mythical, but above all they lead to the problems of research methodology, and thus they are the basis on which a researcher who wants to understand what myths entail.
The Ethnological Dictionary of Ryszard Tomicki claims that the notion of myth should be understood as three basic planes of meaning. The first, the narrowest one, treats myth as a story. The second, extended one, assumes that myth is a carrier of archaic worldview. The third, however, assumes that myth is a universal form of consciousness. The first plane, being an element of oral culture, is fundamentally different from an equally archaic fairy tale or legend. The structurally important elements contained in it are connected with the categories of etiological approach to the origins of time, the appearance of the Living Space and the first model mythical actions of characters - gods, ancestors or heroes. Such myths have a cosmic dimension, because the deeds described in them have cosmic and human consequences. For this reason, myth is sometimes referred to as a story about gods and heroes, as well as a story about the beginnings of everything that is, and finally also as an instructional story. The archaic myth describes not only the ontological character of the world and its inhabitants, but also its axiological structure responsible for the existence of an ordered Cosmos and amorphous and destruc- 
tive Chaos. The myth that goes beyond its narrative formula and becomes present in the mythical rirual introduces a different approach to its content than the one based on understanding the narrative formula. Maciej Czeremski describes the precise analysis of this phenomenon. Myth becomes the basis not only for understanding the world through its narrative image, but also for religious «subordination» to man through religious attitudes, rituals or magical treatments. This type of perception of the world is characteristic for «untamed thinking» and has its own rich literature. It is connected with the animation of the world, often leading to its extreme anthropomorphisation. It creates not only a model of the Living Space, but also defines the way in which man exists in it, creating the basis for the creation of organizations of primitive societies. Myth in the third sense is treated as a universal phenomenon. We can find it in the works of both Zygmunt Freud and Carl Gustav Jung as elements of content pushed into the subconscious. What is important, however, is that the myth seen in this way shows us an important aspect of its structure connected with the two layers of human thought. This can combine subconscious content with conscious content, as well as the form of mythical pictorial thinking, characteristic of the archaic myth, with abstract scientific thinking. Such a perception of myth, according to what Leszek Kolakowski wrote in The Appeal of Myth, allows us to combine the contents of everyday human experiences in the theological perspective by referring to the reality of the unconditional type.

Myth is, as you can see, not only a multifaceted story, but also a multifaceted one. That is why his research is so fascinating and difficult. The myth in the semi-sphere of contemporary culture combines religious and anthropological content. Initially, therefore, we can accept three planes of myth that interest us.

The first symbolic one is connected with the views of Paul Ricoeur contained in the work Symbolism of Evil. The myth is treated as a religious symbol developed in the story. Of course, it should be re- membered that a religious symbol is a very specific sign. According to Paul Tillich, it has a plane and two intentions. The first one is connected with the real, empirically experienced world of the human environment and is subject to rationalization. It also refers the viewer to the nonempirical dimension of reality, defined by philosophers of religion as a higher-order reality. The myth in this case makes a narrative attempt to explain the contents of a symbol that is culturally important for a particular community. To understand such a myth is to get closer to the symbolic content that in some way funds the cultural identity of the community in which it appears. An important problem resulting from the specific ontology of a religious symbol is that it escapes in the field of the second, intuitively perceived plane of interpretation and hermeneutical interpretation.

In the second case, the myth is treated as an instructional story that defines both the boundaries of the Living Space and the norms that govern it. This is all the more important because thanks to Mircea Eliade's research we gain access not only to mythical narratives describing the «invasion of sacrum», but also to the accompanying actions of mythical heroes, whose effects have not only a cosmic range, but are still valid today.

The third case, probably the most attractive from the perspective of contemporary man, combines the images contained in the two previous planes with elements present in contemporary challenges present in the world and human culture.

Speaking of myth, there are three basic surfaces of meaning. At the religious level we will have to deal with various aspects of religious experience (characteristic of both cosmic and revelatory religions). Here there are elements of narration and images characteristic of archaic myths, elements of myths and mythical rituals themselves, as well as all the extremely rich religious symbolism. On the cultural level, of course, all the above mentioned elements will also be present, if only because religion belongs to culture. However, the most important in this case will be the aspects of degraded myth, first 
present in the epic and fairy tale, and then penetrating into the whole area of literature and art using mythopoetic techniques. Myth on this surface will appear in both didactic and speculative functions, and will be less frequently reduced to a pure form of aesthetic ornament. At this level, myth will be attractive both in the aesthetic and folk perspective, playing with the viewer with its narrative, and in the cognitive perspective, when it will allow the viewer to understand the nature of the cosmos and human condition through mythical figures developed into narratives. It is here that the contents of the mythical message presented in subsequent cultural artefacts will remind about the most archaic aspects of the human condition, shape human attitudes considered by given cultures to be the most optimal in a given environment, but also provoke questions or even a rebellion against what is alien in the meaning of radical man, and thus individualize not only the understanding of the subject, but also its perception of the human environment. The mythical or mythopoetical message perceived in this way leads the attentive recipient to a more complete understanding of himself, by writing his own condition in events that took place in illo tempore.

The last level is connected with the political myth, focused on the specifically understood social and political praxis. Not only will there be formulas for desired and politically accepted attitudes of heroes, kings and other types of leaders, but also a specific formula of paidei based on epics, as was the case in classical Greece or other types of political myths, which was particularly visible in modern societies.

As we can see, the formula adopted in this way of reading myth reveals its three fundamental aspects from the perspective of human existence. The first one is connected with being in the face of numinosum, manifesting itself in various invasions of sacrum. The next one is connected with being towards the Other who, although not his own in cultural sense, does not belong to the world of nature as animals and becomes a proto-figure of neigh- bour or the other-self. The third plane defines being towards the Alien, both the one whose alienation has cultural sources (language, customs, religion, etc.) and the one whose alienation is founded by axiology or ontology, or even metaphysics.

One of the most interesting of the great catalog of mythical narratives is the heroic myth. This type of myth is all the more important when one remembers that myth always appears in situations that are somehow important to a human being. Hans Blumenberg wrote about this very extensively in his Work on the myth. The heroic myth contains symbolic contents developed in many aspects in the narratives. In this respect, the hero becomes a representative of the human community, who is actively confronted with what is contained in the religious/mythical symbol, what emanates through it and influences the constitution of the human world. Thus, in the heroic myth we have the gesta described, i.e. decisions, attitudes and actions of a man who, in relation to the numeral, manifesting himself in the surrounding world, not only limits human autonomy, but even reduces it. Being a hero means being in the face of what remains hidden in the symbolic content and determines the human model of existence. For this reason, the hero's actions described in the myth become a model story whose plot reveals not only the boundaries and norms governing the world and human existence, but also human attitudes and actions testing to what extent these limits can be exceeded. In heroic myths, the hero can be realized by a god, a demigod, an ancestor or a human being. It may also be a supernatural figure, or even a trickster. Hero is confronted with what is alien. Threats faced by heroes manifest themselves both subjectively, taking on the form of opponents - usually supernatural ones - and objectively, when they enter into tabooed areas or even into the beyond worlds or areas alien to human existence.

There are three important aspects to the mythical pattern of a hero. The components of this pattern are inscribed in the concrete in statu nascendi happening in a specific mythical narrative. The plot 
of these myths allows us to discover the nature of the hero himself relatively precisely. It consists of supernatural elements, often resulting in a hybrid aspect of the hero's ontology. It has its own numinal source, but it is often rooted in the human subject and is almost always used to clearly define the boundaries of human autonomy in the field where our existence meets that which is alien. However, qualities such as courage, tenacity and prudence are already culturally valued in human action. Embedding them in heroic forms can only enhance their cultural function, pointing to their role in the human quest for self-determination and liberation from the influence of the determination of the Living Space. Thus, the heroic myth contains not only images of heroic acts in the sense of expedition or struggle, but also intellectual effort allowing to understand the mechanisms governing the space in which the hero is faced with what is alien.

\section{Mythologizations}

Myth, as one of the most archaic narrative formulas of man, ceased to be a living narrative when it ceased to be a domain of religious experience. However, its specific structure and content caused the myth not only not to be culturally forgotten, but also to be incorporated into younger stories, introducing its multi-faceted and ambiguous content hidden in figures and mythologies. The degraded myth, i.e. the one introduced to non-religious cultural narratives, is still a carrier of symbolic meanings. New times bring both new challenges and new generations to the same eternal human questions. This results in the creation of new narratives developing in specific aspects forced by the challenges of everyday life.

Mythologization will be both a process of creating an archaic myth and a process of creating a degraded version of it based on this myth, but based on mythopoetic principles. In order to understand the meanings contained in mythical narratives, it is necessary to realize the mechanisms that accompa- nied their creation. One can use the works of both Mircea Elidae and Eleazar Mieltinski. The most interesting mechanism, however, seems to reflect Gerardus van der Leeuw in The Phenomenology of Religion, combining in it the experience of the man's Power, Willingness, and finally the Name associated with an important event.

However, already in the case of mythologization, i.e. secondary narration of the content and images contained in myths, this process is subject to considerable complications. The process of mythologization itself binds the imaginary content necessary to create new aspects and horizons in which mythical matrices or their elements are inscribed. They combine the archaic with the contemporary. Mythologization may be a formal renarration of specific myths, using more modern stylistic means introduced by the creators in order to achieve specific aesthetic or cognitive effects. This mechanism has been described in detail by Harry Slochower. The use of mythical narrative elements is often associated with far-reaching reductions, as both Mieletinski and Elidae have pointed out, and it is thanks to them that the mythical hero can be reduced to a functionally described literary hero of a criminal or adventure novel. However, he should always realize the most archaic aspects of the hero. These may be contained, for example, in the monomyth structure described by Joseph Campbell. It must not be forgotten that both Cambell's and Slochower's proposals are largely related to Jung's views on the nature of myths. That is why their proposals will be so important in such a way as to use heroic figures which, as a result of narratives describing them, will allow for some form of rationalization of subconscious sources of their activity. Apart from the formal aspect related to the figure of the quest, it is also possible to subject the hero's figure to such creative efforts that the content contained in their deeds will be precisely placed by the creators in artistic structures with specific goals. Such procedures are possible thanks to the proposals of Paul Ricoeur and Robert A. Heinlein. Ricoeur assumed that a literary work 
could in certain situations serve as a «moral laboratory». Thus, the character in the text can be organised in such a way as to highlight the moral aspects of its activity. However, reading such a text, if it meets the conditions of a hermeneutical interpretation, will allow the viewer not only to understand the moral essence of the hero's actions, but also, without participating in the events in illo tempore, to broaden his horizon of meanings to include the content created as a result of the hero's actions or the character imitating him in a mythologized narrative. Accepting the perspective proposed by Ricoeur, we are confronted with two important problems. The first one is connected with the activity of the creator of the mythological project, because it is he who has to make the original interpretation of the moral nature of the hero and include it in his own artistic project so that it contains both elements of the mythical matrix and innovative, author's perspectives. They will decide in what aspect and at what level of meaning the viewer will try to understand it. The second problem is the competence of the viewer. The higher the probability, the greater the probability that in the process of understanding the viewer will touch both the most archaic in the mythical message and the one who will take it in his own horizon of moral understanding of himself and the surrounding world.

Heinlein's artistic idea brings yet another possibility of mythologization. Although it is connected with the work of science fiction, the idea allows us to transcend the poetics of this type of writing. Of course, this is about the concept of speculative fiction. It is a procedure consisting in introducing the hero into new, often indescribable or non-existent states of things and testing his actions and their consequences. Treatment with a similar specification of functions was also used in ancient Egypt during the transition from mythical to theological thinking with the use of mythopoetic speculation, as Edwin Olivier James wrote. This mechanism allows not only to introduce the hero's character into culturally alien worlds, but also to use the character of the hero in such a way as to extract from it or highlight in action a specific level of meanings inscribed in this character.

\section{The mythological hero}

The project to mythologize a hero always starts with the creator. Not only from the richness of his imagination and artistic abilities, but above all from his competence in the mythical matrix. It is nothing more than a cultural record of archaic mythical narratives. The artist who undertakes the creation of the mythopoetic figure of a hero always, in some way, more or less conscious, refers to the mythological matrix. It is the information contained in it that defines the mythical world, the rules that govern it and the functions of beings existing in it, including heroes. Knowledge of the matrix allows the creator to get acquainted with the features attributed to the hero in his natural environment and the functions he was supposed to perform in it. Thanks to the knowledge of the matrix, the creator not only learns the specificity of the Living Space, its specific structure, phenomena occurring in it and the rules governing them, but also the individual specification related to specific myths. The last aspect of the knowledge of the matrix is, of course, connected with the knowledge of the full story of the heroic myth, and the best of all available versions of it. Obtaining a complete knowledge of the matrix is often only a certain ideal assumption. It is connected with the very nature of the myth and the expectations of the creator. One of the effects of such a state of affairs is, in consequence, a differentiated and multilevel model of possible mythologies of the hero. Basically, two most important levels of the hero's mythologization procedure can be identified. The first, content-based, is connected with various renarrative treatments based on source mythology. The second is formal and focuses on the formal schema concerning the structure of the hero or his activity inscribed in the monomyth plot. 
Due to the artistic strategies used in relation to the mythical matrix, five basic creative models of creating a mythologized hero can be identified.

The first one, complete, is based on the most faithful, most often content-based, concrete myth in a literary work. A classic example here are novels like Heros should be one, or The King should die. In both cases we are dealing with a relatively complete renarration of source myths. In Mary Renault's novel, this is reduced to one fundamental mythologist. Ukrainian writers, using the artistic pseudonym Henry Lion Oldi, while creating the character of Heracles, used much more variants of the myth connected with it, present in the texts of ancient mythologists. A full, or in fact complete, renarration can be, as can be seen from both examples, associated with one version of the myth or based on more of them. It is important that these versions are considered canonical by researchers and treated as such in cultural and research traditions. In this creative model, the descriptions of mythical reality, the essential features of the hero and his actions are repeated. However, the author's specific innovation of perspective is allowed, allowing for such a renarration, which will aim at emphasizing those layers of meanings that the author will consider important.

The second model should be called partial, because it is based on a far-reaching reduction of the content contained in the matrix. The sender most often uses only the schematic outline of the mythical universe. For example, it is connected with events assigned to the moment in statu nascendi or it inscribes certain features of the hero or his actions in the created hero. This can be seen in the use of apocalyptic motifs in contemporary cinema in productions based on Marvel's comics or CD Project. These motifs are also very popular in other mass cinema productions. Another type of this type of treatment is visible in many productions that are in line with the conventions of thriller or detective story, in which the main character performs the mythical function of fighting good with evil and order with chaos.
The third model is the attribute model. As a rule, it is based on such reduction operations in relation to the material contained in the mythical matrix, which results in the separation of certain attributes in the artistic material, important from the artist's point of view, at the cost of removing or minimizing the significance of other attributes. There are several characteristic types of procedures in this area. The first one is connected with mythopoetical reduction. As a result, in Heracles' mythology the most important will be the strength of the hero and its role in his actions, in Thor's case - violence and strength, and in Loki's case - unpredictability and amorality. In addition, this type of reduction is based on the most famous feature elements of specific mythologists, which inevitably also leads to a reduced image of the hero. Another type of reduction is physiological reduction, based on which Tiresias is perceived by his blindness, Valkyrie receives wings, most epic heroes have superhuman powers, allowing them to do things that are impossible for other people to do. Another type of reduction involves operating on mythical artifacts such as winged boots, Cadet Hermes or Iris, Egida, which was the shield of Zeus, Mjöllnir Thor, Eros' golden and lead arrows or Aphrodite's apron. Still another type of reduction associated with hybrids or even monsters. In this way, one introduces to the plot such beings as Medusa, Kraken, Minotaur, Cerberus or Hydra, which appear in tradition in certain semantic connotations. The authors often also reach for the spaciological reduction connected with specific elements forming the world of the Living Space. They operate on spatial structures of the afterlife such as Hades, Olympus, Avalon or Asgard. One of the most interesting reductions is related to heroic acts. It consists in linking a particular character with a heroic act known from tradition. It can be a journey through the hereafter, a trip to the treasure, or the defeat of a monster. These reductions usually function in two models. The first one is connected with the mythical matrix and its protagonists, but the renaration is based on the aspects of the mythical plot reduced 
by the sender. In the second case, the mythical element with cultural meanings assigned to it is introduced into worlds not culturally connected with the mythical matrix.

Another model of mythology is the functional model. The classic type is, of course, to reduce the hero to the function of a participant of the expedition - a quest. It is usually based on the reduction of the paradigm inscribed in the monomyth. It can be a reduction reduced either to one particular expedition or to some element of it, such as the tests to which the hero is subjected during the expedition. He can act as a conqueror emphasizing new spaces of human autonomy, as is the case with heroes entering the underworld. He can act as a defender protecting the autonomy of the community against various forms of threat. A specific form of this type of reduction is the figure of the avenger present, for example, in the well-known series Avangers by Marvel. One of the most interesting meanings, however, is the extremely complicated, both axiologically and functionally, figure of a trickster. He can be both an antagonist and a protagonist. Its limitlessness, embedded in mythical symbolism, introduces irrational elements that are necessarily inscribed in the construction and existence of the Living Space.

The last model of mythologization is based on mimetic treatment of the matrix. It uses images of mythical figures present in the cultural thesaurus.

\section{The relation of mythology to the mytho- logical model}

Depending on the model of mythologization adopted by the artist, it can be assumed that the effects of artistic activities will be able to appear in four basic forms. The first, most faithful to the mythical model will be based on the mechanism of a certain mimetic representation of the aspect or meaning contained in the mythical matrix chosen by the artist. This is what happens, for example, in Hobbit, in whose feature structure we find an exact reflection of the structure of the quest. Another form is based on speculative use of mythical content, which can be seen in Dan Simmons' Ilion, who, using the content in Homer's Iliad as a basis, introduces mechanisms completely alien to Homeric content, testing the essence and nature of Homeric heroes. A specific form of the speculative model is a futuristic, or rather futurological, project. It may use a mythological matrix, but by introducing posthumanistic and transhumanistic elements into it, it often completely deprives it of its numeral element, with all the consequences of this procedure. This results in a complete reversal of some aspects and related meanings inscribed in mythical narratives. Leading to a situation in which man creates gods, and not the other way round, as is the case with Levi Tidhal's Central Station, or man, thanks to new technologies gains all aspects of transcendental existence, ceasing to be man in the ontological aspect and acquiring divine features, such as immortality, which is visible in the trilogy Void. The last model is connected with the polemical reference of the artist to the content of the mythical matrix. Then there will appear mythical figures, which are given a completely different from the model aspect of meaning. The good becomes the bad, the bad becomes the defender, the order of the Living Space is set by technical artifacts. In such projects, mythological treatment is often based on the mechanisms described by Roland Barthes in his work entitled Mythology. New ones, like in Hellboy or Ghost Rider films, replace the removed meaning connected with the matrix. Both these productions had their originals in comics and it was the comic artists who created both the characters and the model of the plot based on the polemical use of specific mythologists and sometimes even theologians.

Re-narrative actions, which are often the fundamental actions of artists in relation to mythical matrices, may therefore, as it has been shown above, introduce mythical content into the texts of culture in a total or partial perspective. However, it seems more important what function the creator uses these elements in. Among the functional mod- 
els mentioned above, there is one more, extremely important model of myths manipulation. Of course, this is about the aletheic function, which consists in reintroducing into contemporary culture mythical contents that have been forgotten culturally.

The functional aspect of the use of mythical elements by the creators is necessarily linked to a reduction creating a meaning perspective through which the sender wishes to introduce the chosen aspect or meaning field of the myth into his own artistic project. This leads us to the point where in an artistic project the perspective in which the mythologized hero will be shown is determined. It can be initially assumed that two perspectives are extremely important in this case. The first one, connected with the aletheic formula of artistic activities, not only introduces the hero's figure itself into cultural memory anew, but first of all opens for contemporary users of culture the whole mythological paradigm in which a given figure existed in its matrix. Its fundamental value is its action, which results in restoring authentic, i.e. model content of mythical narratives to the semi-sphere. It is only as a result of such actions that one can talk about artistic practices aimed at building a paradigm containing the features that make up the figure of a hero. It is about his ailments such as strength, bravery, prudence, responsibility, but also relentlessness, violence, or even madness. In such a manifested collection of heroic data, further artistic actions are possible only. Their main aim is to present our awareness of all the values and aspects of heroism, making them an object of not only emotional experience, but also of the process of secondary understanding described by hermeneuts. It is this secondary understanding that may allow the contemporary viewer to broaden his or her own horizon of perceiving his or her surrounding world with the cultural content of archaic, which is the basis of human culture and existence. This results, on the one hand, in a process of rationalisation of heroic deeds and attitudes. On the other hand, it leads to the creation of wishful thinking heroes present in contemporary popular culture, acting as representatives of a threatened community, protecting the rights of its members to selfdetermination and autonomy. As a result, the artistic use of mythical heroic models leads to evocation to cultural memory through rationalization of symbolic content inscribed in their essence, up to the creation of new models, which are the result and effect of modern times and the expectations they give rise to.

Among the most frequently appearing new models of heroes present in contemporary popular culture, several basic types can be identified. The first one is related to the figure of a child. This is usually associated with writing the character of the child hero into the plot of the quest, as is the case in the animated film Coco, where the main character is forced to travel to the beyond worlds. He experiences many attempts and restores the lost order. All the features of the protagonist are realized by this childlike character. The only difference is that the pattern, which is the child's hero, is more inscribed in the model of processes connected with maturing and searching for one's own place in the world and its deep understanding. A specific variation of the new hero's model is to put him in front of what is inhuman. He may experience this in both subjective and objective references, and even may be subjected to the process of losing important aspects of humanity. This model most frequently appears in literature related to posthumanism and transhumanism, as well as in the projects of technological interference in human nature. It is also here that numinal and non-traditional forms of alienation and the attitudes towards them and their potential consequences connected with their manifestation in the human world are discovered, or rather tested. In both cases, the new figures of heroes are used to perform ludic functions, but also to speculate on potential threats to human autonomy and ways of survival. The increasingly strong secularization of popular culture does not always result in a departure from forms of religious thinking, as Daniéle Hervieu-Léger has already pointed out, but rather in their use in a new 
way, not necessarily related to the canonical model. This results in the appearance of heroes, not so much liminal in their essence as simply demonic. The demonism of the new hero does not exclude his attitude protecting what is good. Such a figure of a hero changes not only the mythical model of cosmic order, but also responds to the cultural demand for active heroes from previously rejected models. Such a model can be found, for example, in the novels dedicated to Dora Wilk. The last two models of heroes are connected with the evolution of popular literature and the artistic development of its figures and images. One of the effects of this phenomenon is the departure from simple hero visualization in favour of a collective hero, which we see in The Lord of the Rings of Tolkien in relation to the ring team, or a hidden hero such as Sam, who appears in the cited novel. The last type of hero is connected with his fall or defeat, as a fundamental aspect of his actions, which can be found in The Songs of Ice and Fire, or his amoral attitude, which can be seen in The Malaysian Book of the Fallen.

As a result, there are three perspectives of artistic activities connected with heroic mythologies. The first one is based on a game with hero attributes. They most often have a causal function, calling the hero to heroic actions. They can be so characteristic of Marvel's or CD Project's heroes as artifacts or attributes. Another case is related to situational conditions, where an ordinary hero takes actions that make him a hero, as was the case in Avatar. The second perspective is based on artistic games with reductions. A mythologized hero can be reduced to various forms of tremendum, such as Hulk. Otherwise, it may be reduced to a tremendum, without taking into account other aspects of the figure, an example of which can be found in Twilight's tetralogy. It can also be re- duced to specific aspects related to the attitude, deeds or choices of mythologized heroes. The result can be positive figures, Captain America, or negative figures, like Hannibal Lecture.

Faced with mythical trials, the mythologized hero is most often confronted with the challenges posed by new technologies or the alien. However, the effect of such actions is always to take up two most archaic issues: human autonomy and the essence of humanity and its borders. Paraphrasing the aforementioned sentence by Ricoeur, which states that «a symbol gives food for thought», one can state that in the most desirable artistic version, a mythologized hero can be used for the broadly understood procedure of aletheization of mythical contents inscribed into mythical thinking related to the figure of a hero. However, it is only on the basis of this model that, thanks to the deeply humanistic aspects of the meanings of the mythical model of perceiving the world, restored to contemporary consciousness, that the effort can be made to build such mythological figures that will capture both the problems of the contemporary world and heroic attitudes. Thus, the figures of a mythologized hero should provoke to philosophical problematization of the world of human surroundings, beginning with the question asked by Greek creators of philosophy: dia ti, that is, why? The cultural attractiveness of the return to mythical models can be seen both in their aesthetic attractiveness and in the need, inherent in human nature, to search for answers to existential questions. Since they are not sought for various reasons in philosophy or religion, art returning to mythical ambiguity and multi-facetedness, bringing contemporary man the possibility to return to the certainty of attitudes and choices sanctioned by mythical tradition, becomes in a natural way a space of essential meanings. 


\section{Богдан Троча Герои заставмяют задуматься}

Аннотация. Автор рассматривает механизмы мифологизации фигур современных героев в новейшей культуре. Он также анализирует компетенцию созАателей таких фигур и их связь с самим процессом мифологизации и описывает причины этого явцения в современной кумьтуре.

Ключевые слова: миф, мифотворчество, массовая митература.

\section{Богдан Троча Герої змушують замислитисяї}

Анотація. Автор розглядає механізми міфологізації постатей сучасних героїв у новітній культурі. Він також анаАізує компетенцію творців таких фігур і їхній зв'язок з самим процесом міфологізації та описує причини цього явища в сучасній культурі.

Ключові слова: міф, міфотворчість, масова мітература. 